\title{
Risk factors for Low Anterior Resection Syndrome (LARS) in patients undergoing laparoscopic surgery for rectal cancer
}

\author{
Antonella Nicotera $^{1}\left(\mathbb{D} \cdot\right.$ Ezio Falletto $^{1} \cdot$ Alberto Arezzo $^{1} \cdot$ Massimiliano Mistrangelo $^{1} \cdot$ Roberto Passera $^{2}$. \\ Mario Morino ${ }^{1}$
}

Received: 12 July 2021 / Accepted: 31 December 2021 / Published online: 8 February 2022

(C) The Author(s) 2022

\begin{abstract}
Background Total mesorectal excision (TME) represents the "gold standard" of rectal cancer surgery. In locally advanced lesions neoadjuvant treatments (e.g. radiotherapy-nRT, radio chemotherapy-cnRT) have been shown to improve TME oncological results, reducing local recurrences rate. Nevertheless, these treatments have significant functional consequences impacting patients' quality of life (QoL). The resulting syndrome is known as Low Anterior Resection Syndrome (LARS). The purpose of this work was to evaluate the association between risk factors and the development of LARS in a prospective series of laparoscopic sphincter-saving TME.

Methods The study was conducted as a retrospective observational epidemiological study of a prospective database, including all patients undergoing laparoscopic anterior resection surgery for rectal cancer at our Unit from 1st January 2013 to 31st May 2018. The diagnosis of LARS was performed using the LARS Score. We classified risk factors in patient-related, pre-, intra- and post-operative factors.

Results The sample included 153 consecutive patients. Forty-one were affected by "low" rectal cancer, 74 by "middle" rectal cancer, 38 by "high" rectal cancer. The prevalence of overall LARS (major LARS + minor LARS) in our series was $35.9 \%$ (55/153 cases). Association between nRT and overall/major LARS was significant (respectively $p=0.03$ and 0.02 ). Distal localization of tumor was also significantly associated with LARS [overall LARS $(p=0.03)$, major LARS $(p=0.014)$ ]. Conclusions In our study, neoadjuvant radiotherapy and tumor localization resulted independent risk factors for LARS after laparoscopic sphincter-saving TME. Tumor localization in the "middle" and "high" rectum resulted a protective factor compared to the localization in "low" rectum.
\end{abstract}

Keywords Rectal-cancer $\cdot$ TME $\cdot$ Laparoscopy $\cdot$ LARS $\cdot$ Radiotherapy $\cdot$ Tumor-height

Total mesorectal excision (TME) introduced by Heald in 1983 represents the "gold standard" of rectal cancer surgery [1]. When technically feasible and oncologically safe, surgeons strive to reconstruct intestinal continuity by sphincter saving techniques, progressively limiting in recent years the rate of abdominoperineal resection. In locally advanced lesions neoadjuvant treatments (e.g. radiotherapy, radio chemotherapy) have been shown to improve TME oncological results, reducing local recurrences rate

Antonella Nicotera

antonella.nicotera@gmail.com

1 Department of Surgical Sciences, University of Torino, Corso Dogliotti 14, 10126 Torino, Italy

2 Department of Medical Sciences, University of Torino, Torino, Italy
[2-5]. Regrettably, the abovementioned treatments, although very effective from the oncological point of view, are associated with functional consequences significantly impacting patients' quality of life (QoL). The resulting syndrome is known as Low Anterior Resection Syndrome (LARS). In 2012, Briant proposed a universally accepted definition of LARS: "Disordered bowel function after rectal resection, leading to a detriment in quality of life" [6]. LARS includes a variety of symptoms related to bowel dysfunction, such as defecation urgency, gas and stool incontinence, stool fragmentation, and obstructed defecation. Such symptoms are time-correlated, generally regressing in a variable interval from 6 to 18 months, time necessary for the neo-rectum to "rehabilitate" and time beyond which further improvements, if not occurred, become unlikely and the syndrome is considered irreversible. LARS is a complex syndrome, resulting 
from a multifactorial genesis. Best known LARS risk factors are lesion of the anal sphincter [7-10], TME and height of the anastomosis [11-15], neoadjuvant radiotherapy (nRT) [13-17], type of anastomosis and configuration of the neorectum [18], motility of the neorectum [19, 20], presence of diverting stoma and timing of its closure [21]. Currently, several scores are available for the diagnosis and classification of LARS. The most used is the LARS score, according to which the syndrome is divided into minor LARS and major LARS [22]. As well as the etiopathogenesis, the treatment is also multifactorial and in most cases symptombased. Treatment includes anti-diarrheal drugs, anal plugs, biofeedback therapy, pelvic floor rehabilitation, colon irrigation and nerve stimulation [23].

The advent of laparoscopic surgery in the treatment of rectal cancer has improved the postoperative course, reducing both hospital stay and time to resume daily activities. Nevertheless, data on function outcome of the laparoscopic rectal resections are scarce and specific data on LARS are lacking. The purpose of this work was to evaluate the association between anamnestic, pre-, intra- and post-operative risk factors and the development of LARS in a prospective series of exclusively laparoscopic sphincter-saving TME.

\section{Materials and methods}

\section{Study design}

The study was conducted as a retrospective observational epidemiological study of a prospective database, including all patients undergoing laparoscopic anterior resection surgery for rectal cancer at our Unit from 1st January 2013 to 31st May 2018. The diagnosis of LARS was performed using the LARS Score, resulting from a questionnaire which consists of 5 questions, whose answers are associated with a score, the sum resulting in the final score. A score from 0 to 20 indicates absence of LARS, 20 to 29 minor LARS, 30 to 42 major LARS [22]. The Score was calculated through the reports of post-operative follow-up surgical visits or through a telephone interview, after checking the presence of informed consent to the processing of personal data for purpose of scientific research. The calculated LARS score referred to the first 12-18 months after surgery for each patient. The study was conducted in good clinical practice according to the Helsinki Declaration of 1975 and subsequent modifications.

\section{Aim of the study}

The aim of the study is to estimate the prevalence of LARS in our Center and to define LARS risk factors in patients undergoing laparoscopic surgery for rectal cancer.

\section{Exclusion criteria}

Patients undergoing laparoscopic surgery converted to open technique, patients who did not give their consent, patients who developed post-operative complications requiring a permanent stoma, deceased patients whose post-operative course could not be reconstructed and patients lost to follow-up were excluded.

\section{Population risk factors}

We distinguished between patient-related risk factors and pre-, intra- and post-operative factors. Patient-related risk factors are: gender, age $>65$ years, smoking, body mass index (BMI), cardiovascular disease (arterial hypertension, coronary heart disease, cardiomyopathies, electrical disorders), diabetes, neurological/neurodegenerative disorders, chronic obstructive pulmonary disease (COPD), chronic corticosteroid therapy, dyslipidemias, previous abdominal and/or pelvic surgery, collagenopathies, immunodeficiency syndromes. Pre-operative factors are: nutritional status (albumin and protein levels), hemoglobin level, nRT, localization of the tumor expressed in $\mathrm{cm}$ from the anal margin at rigid rectoscopy ("high" when located between 11 and $15 \mathrm{~cm}$, "middle" between 6 and $10 \mathrm{~cm}$, "low" up to $5 \mathrm{~cm}$ from the anal margin). Variants of surgical technique are: colorectal/colo-anal anastomosis type [straight colo-rectal (SCR), side-to-end (STE), end-to-side (ETS)], TME, diverting stoma. Post-operative factors are: surgical complications, need for re-intervention, blood transfusions, adjuvant chemotherapy (CTa), adjuvant radiotherapy ( $\mathrm{RTa}$ ), timing of closure of diverting stoma (earlier or later than 3 months after the index surgery).

\section{Statistical analysis}

Data were analyzed using descriptive and inferential statistics. Categorical variables were expressed as absolute/relative frequencies. The impact of all risk factors was calculated using Fisher's Exact Test for categorical variables and Mann-Whitney's test for continuous variables. All $p$ values reported were obtained by the 2 -sided method, at the conventional significance level of 5\%. Univariate and multivariate binary logistic regression was performed. Data were analyzed starting from September 2020 by R 4.0.2 (R Foundation for Statistical Computing, Vienna-A, http://www.R-project.org).

\section{Results}

The sample included 153 consecutive patients with a median age of 66 years (range 34-91). Forty-one patients were affected by "low" rectal cancer, 74 by "middle" rectal 
Table 1 Patients' main characteristics at baseline

\begin{tabular}{|c|c|c|}
\hline & Risk factors & $N^{\circ}$ patients/tot $(\%)$ \\
\hline \multirow[t]{13}{*}{ Anamnesis } & Male gender & $90 / 153(58.8)$ \\
\hline & Age $>65$ years & $80 / 153(52.3)$ \\
\hline & Smoking & $25 / 153(16.3)$ \\
\hline & $\mathrm{BMI}>30 \mathrm{~kg} / \mathrm{m}^{2}$ & $11 / 153(7.2)$ \\
\hline & Cardiovascular disease & $87 / 153(56.9)$ \\
\hline & Diabetes & $23 / 153(15.0)$ \\
\hline & Neurological disorders & $6 / 152(3.9)$ \\
\hline & COPD & $13 / 153(8.5)$ \\
\hline & Corticosteroid therapy & $2 / 153(1.3)$ \\
\hline & Dyslipidaemia & $33 / 153(21.6)$ \\
\hline & Previous surgery & $37 / 153(24.2)$ \\
\hline & Collagenopathies & $3 / 153(2.0)$ \\
\hline & Immunodeficiency & $0 / 153(0.0)$ \\
\hline \multirow[t]{9}{*}{ Pre-operative data } & Albumin level $<3.5 \mathrm{~g} / \mathrm{dl}$ & $0 / 148(0.0)$ \\
\hline & Protein level $<6.6 \mathrm{~g} / \mathrm{dl}$ & $40 / 136(29.4)$ \\
\hline & Hemoglobin $<12 \mathrm{~g} / \mathrm{dL}$ & $36 / 152(23.7)$ \\
\hline & $\mathrm{nRT}$ & $46 / 153(30.1)$ \\
\hline & Localization of tumor & \\
\hline & $0-5 \mathrm{~cm}$ & $41 / 153(26.8)$ \\
\hline & $6-10 \mathrm{~cm}$ & $74 / 153(48.4)$ \\
\hline & $11-15 \mathrm{~cm}$ & $38 / 153(24.8)$ \\
\hline & Bowel preparation & $153 / 153(100.0)$ \\
\hline \multirow[t]{6}{*}{ Surgical technique } & Anastomosis & \\
\hline & SCR & $145 / 153(94.8)$ \\
\hline & STE & $7 / 153(4.6)$ \\
\hline & ETS & $1 / 153(.7)$ \\
\hline & TME & $116 / 151(76.8)$ \\
\hline & Stoma & $73 / 153(47.7)$ \\
\hline \multirow[t]{6}{*}{ Post-operative data } & Complications & $33 / 153(21.6)$ \\
\hline & Re-intervention & $8 / 145(5.5)$ \\
\hline & Blood transfusion & $9 / 152(5.9)$ \\
\hline & CTa & $64 / 148(43.2)$ \\
\hline & RTa & $3 / 148(2.0)$ \\
\hline & Stoma closure ( $>3$ months) & $61 / 73(83.6)$ \\
\hline
\end{tabular}

Bold type indicates the most frequent anamnestic risk factor in the population

$B M I$ body mass index, $C O P D$ chronic obstructive pulmonary disease, $n R T$ neoadjuvant radiotherapy, $S C R$ straight colo-rectal, $S T E$ side-toend, ETS end-to-side, TME total mesorectal excision, CTa adjuvant chemotherapy, $R T a$ adjuvant radiotherapy

cancer, 38 by "high" rectal cancer. Eighty (52.3\%) patients were over 65 years of age. Sixty-three $(41.2 \%)$ patients were female and $90(58.8 \%)$ male. BMI was $>30 \mathrm{~kg} / \mathrm{m}^{2}$ in $11(7.2 \%)$ patients. The most common comorbidity was cardiovascular disease (56.9\%), compared to dysmetabolic (diabetes $15 \%$, dyslipidemia $21.6 \%$ ), respiratory $(8.5 \%)$, neurological (3.9\%) and auto-immune (collagenopathies $2 \%$ ) diseases; none of these factors were significant associated with LARS. Forty-six (30.1\%) patients received long course nRT of which 24 patients had "low" rectal neoplasia, 18 patients had "middle" rectal neoplasia, 4 patients had "high" rectal neoplasia. All the patients underwent mechanical bowel preparation. One hundred and sixteen (76.8\%) TMEs were performed, the predominantly colorectal anastomosis was SCR (94.8\%), transanal mechanical ( $89.5 \%$ ), and in $47.7 \%$ of cases ( 73 patients) a diverting stoma was performed. Sixty-four (43.2\%) patients performed CTa and 3 (2\%) patients performed RTa. All baseline patients' characteristics are shown in Table 1. Complications rate was $21.6 \%$ (33 cases). All complications are summarized in Tables 2 and 3.

The prevalence of overall LARS (major LARS + minor LARS) in our series was $35.9 \%$ (55/153 cases), minor $13.7 \%$ (21 cases) and major $22.2 \%$ (34 cases). In our study nRT and tumor localization resulted to be significantly associated with development of LARS. Association between nRT and overall/major LARS was significant (respectively $p=0.03$ and 0.02 ), while the association with the minor form was not significant $(p=0.799)$. Distal localization of tumor was also significantly associated with LARS [overall LARS $(p=0.03)$, major LARS $(p=0.014)$, minor LARS $(p=0.365)]$. All risk factors and the association with the development of minor, major LARS and overall (minor + major) LARS are summarized in Table 4 .

\section{Univariate and multivariate analysis}

On the univariate analysis, the nRT was a risk factor of overall LARS (major and minor) (OR 3.06, 95\% CI 1.49- 6.26, $p=0.02$ ), as well as the localization of tumor $(p=0.003)$. The localization of the tumor in "middle" and "high" rectum were protective factors compared to the localization in "low" rectum (respectively OR 0.28; 95\% 0.13-0.63, $p=0.002$ and OR 0.25; 95\% CI 0.10-0.66, $p=0.005]$. On the multivariate analysis, nRT was confirmed as an independent risk factor for the development of LARS (OR 2.18 CI 95\% 1.00-4.78, $p=0.05$ ), while the localization in "middle" and "high" rectum resulted as protective factors, if compared to the localization in "low" rectum (respectively OR 0.36, 95\% CI 0.15-0.82, $p=0.015$ and OR 0.36 ; 95\% CI $0.13-1.00, p=0.049$ ) (Table 5).

Table 2 Classification of complications according to Clavien-Dindo

\begin{tabular}{llllll}
\hline $\begin{array}{l}\text { Clavien- } \\
\text { Dindo I }\end{array}$ & $\begin{array}{l}\text { Clavien- } \\
\text { Dindo II }\end{array}$ & $\begin{array}{l}\text { Clavien- } \\
\text { Dindo III }\end{array}$ & $\begin{array}{l}\text { Clavien- } \\
\text { Dindo } \\
\text { IVa }\end{array}$ & $\begin{array}{l}\text { Clavien- } \\
\text { Dindo V }\end{array}$ & Total \\
\hline $3 / 33$ & $22 / 33$ & $7 / 33$ & $1 / 33$ & - & $33 / 153$ \\
$(9.1 \%)$ & $(66.7 \%)$ & $(21.2 \%)$ & $(3.0 \%)$ & & $(21.6 \%)$ \\
\hline
\end{tabular}


Table 3 Complications, treatment and corresponding tumor localization

\begin{tabular}{|c|c|c|c|}
\hline Complications & $n$ & Treatment & Tumor localization \\
\hline \multirow[t]{3}{*}{ Anastomotic dehiscence } & \multirow[t]{3}{*}{9} & $\mathrm{n}^{\circ} 4$ Stomas subsequently closed & $\mathrm{n}^{\circ} 1$ High rectum, $\mathrm{n}^{\circ} 3$ middle rectum \\
\hline & & $\mathrm{n}^{\circ} 1$ Suture of anastomosis & High rectum \\
\hline & & $\mathrm{n}^{\circ} 4$ Conservative treatments & $\mathrm{n}^{\circ} 2$ High rectum, $\mathrm{n}^{\circ} 2$ middle rectum \\
\hline \multirow[t]{3}{*}{ Bleeding } & \multirow[t]{3}{*}{8} & $\mathrm{n}^{\circ} 1$ Surgical hemostasis & High rectum \\
\hline & & $\mathrm{n}^{\circ} 6$ Blood transfusions & $\mathrm{n}^{\circ} 4$ High rectum, $\mathrm{n}^{\circ} 1$ middle rectum, $\mathrm{n}^{\circ} 1$ low rectum \\
\hline & & $\mathrm{n}^{\circ} 1$ Conservative treatment & Middle rectum \\
\hline Rectovaginal fistula & 2 & $\mathrm{n}^{\circ} 2$ Stomas subsequently closed & $\mathrm{n}^{\circ} 2$ Low rectum \\
\hline Intra-abdominal infections & 5 & $\mathrm{n}^{\circ} 5$ Antibiotic therapies & $\mathrm{n}^{\circ} 1$ High rectum, $\mathrm{n}^{\circ} 3$ middle rectum, $\mathrm{n}^{\circ} 1$ low rectum \\
\hline Fever & 5 & $\mathrm{n}^{\circ} 5$ Antibiotic therapies & $\mathrm{n}^{\circ} 2$ Middle rectum, $\mathrm{n}^{\circ} 3$ low rectum \\
\hline Pulmonary complications & 2 & $\mathrm{n}^{\circ} 2$ Antibiotic therapies + oxygen-therapy & $\mathrm{n}^{\circ} 1$ Middle rectum, $\mathrm{n}^{\circ} 1$ low rectum \\
\hline Ileus & 1 & Fasting & Middle rectum \\
\hline Linforrea & 1 & Conservative treatment & Middle rectum \\
\hline
\end{tabular}

Table 4 Distribution and analysis of possible LARS risk factors

\begin{tabular}{|c|c|c|c|c|c|c|c|}
\hline \multirow[t]{2}{*}{ Risk factor } & \multirow[t]{2}{*}{$n(\%)$} & \multicolumn{2}{|c|}{ Minor LARS } & \multicolumn{2}{|c|}{ Major LARS } & \multicolumn{2}{|c|}{$\begin{array}{l}\text { Overall LARS } \\
\text { (minor + major) }\end{array}$} \\
\hline & & $n(\%)$ & $p$ & $n(\%)$ & $p$ & $n(\%)$ & $p$ \\
\hline Male gender & $90(58.8)$ & $12(13.3)$ & 1.000 & $19(21.1)$ & 698 & $31(34.4)$ & .733 \\
\hline Age $>65$ years & $80(52.3)$ & $6(7.5)$ & 0.033 & $18(22.5)$ & 1.000 & $24(30.0)$ & 0.174 \\
\hline Smoking & $25(16.3)$ & $5(20.0)$ & .343 & $6(24.0)$ & .796 & $11(44.0)$ & .371 \\
\hline $\mathrm{BMI}>30 \mathrm{~kg} / \mathrm{m}^{2}$ & $11(7.2)$ & $3(27.3)$ & .177 & $4(36.4)$ & .263 & $7(63.6)$ & .057 \\
\hline Cardiovascular disease & $87(56.9)$ & $13(14.9)$ & .645 & $19(21.8)$ & 1.000 & $32(36.8)$ & .866 \\
\hline Previous surgery & $37(24.2)$ & $3(8.1)$ & .410 & 7 (18.9) & .656 & $10(27.0)$ & .240 \\
\hline Protein level < $6.6 \mathrm{~g} / \mathrm{dl}$ & $40(29.4)$ & $5(12.5)$ & 1.000 & $8(20.0)$ & .662 & $13(32.5)$ & .696 \\
\hline Hemoglobin $<12 \mathrm{~g} / \mathrm{dl}$ & $36(23.7)$ & $3(8.3)$ & .408 & $11(30.6)$ & .179 & $14(38.9)$ & .696 \\
\hline nRT & $46(30.1)$ & $7(15.2)$ & .799 & $18(39.1)$ & .002 & $25(54.3)$ & .003 \\
\hline \multicolumn{8}{|l|}{ Tumor localization } \\
\hline $0-5 \mathrm{~cm}$ & $41(26.8)$ & $8(19.5)$ & .365 & $16(39.0)$ & .014 & $24(58.5)$ & .003 \\
\hline $6-10 \mathrm{~cm}$ & $74(48.4)$ & $10(13.5)$ & & $11(14.9)$ & & $21(28.4)$ & \\
\hline $11-15 \mathrm{~cm}$ & $38(24.8)$ & $3(7.9)$ & & 7 (18.4) & & $10(26.3)$ & \\
\hline Bowel preparation & $153(100.0)$ & $21(13.7)$ & - & $34(22.2)$ & - & $55(35.9)$ & - \\
\hline \multicolumn{8}{|l|}{ Anastomosis } \\
\hline SCR & $145(94.8)$ & $20(13.8)$ & 1.000 & $31(21.4)$ & .175 & $51(35.2)$ & .410 \\
\hline STE & $7(4.6)$ & $1(14.3)$ & & $2(28.6)$ & & 3 (42.9) & \\
\hline ETS & $1(0.7)$ & $0(0.0)$ & & $1(100.0)$ & & $1(100.0)$ & \\
\hline TME & $116(76.8)$ & $18(15.5)$ & .408 & $27(23.3)$ & .347 & $45(38.8)$ & .106 \\
\hline Stoma & $73(47.7)$ & $11(15.1)$ & .815 & $21(28.8)$ & .080 & $32(43.8)$ & .064 \\
\hline Complications & 33 (21.6) & $4(12.1)$ & 1.000 & $8(24.2)$ & .814 & $12(36.4)$ & 1.000 \\
\hline Re-intervention & $8(5.5)$ & $1(12.5)$ & 1.000 & $2(25.0)$ & .670 & $3(37.5)$ & 1.000 \\
\hline Blood transfusion & $9(5.9)$ & $1(11.1)$ & 1.000 & $1(11.1)$ & .685 & $2(22.2)$ & .492 \\
\hline $\mathrm{CTa}$ & $64(43.2)$ & $8(12.5)$ & .812 & $18(28.1)$ & .238 & $26(40.6)$ & .392 \\
\hline $\mathrm{RTa}$ & $3(2.0)$ & $0(0.0)$ & 1.000 & $1(33.3)$ & .546 & $1(33.3)$ & 1.000 \\
\hline Stoma closure ( $>3$ months) & $61(83.6)$ & $9(14.8)$ & .686 & $19(31.1)$ & .324 & $28(45.9)$ & .561 \\
\hline
\end{tabular}

Bold type indicates statistically significant $p$-values

$B M I$ body mass index, $n R T$ neoadjuvant radiotherapy, SCR straight colo-rectal, STE side-to-end, ETS endto-side, $T M E$ total mesorectal excision, $C T a$ adjuvant chemotherapy, $R T a$ adjuvant radiotherapy 
Table 5 Univariate and multivariate analysis

\begin{tabular}{|c|c|c|c|c|c|c|}
\hline \multirow[t]{2}{*}{ Variable } & \multicolumn{3}{|c|}{ Univariate analysis } & \multicolumn{3}{|c|}{ Multivariate analysis } \\
\hline & OR & $95 \% \mathrm{CI}$ & $p$ & OR & $95 \% \mathrm{CI}$ & $p$ \\
\hline Gender (Male) & 0.85 & $0.44-1.67$ & 0.643 & - & - & - \\
\hline Age $>65$ years & 0.60 & $0.31-1.17$ & 0.135 & - & - & - \\
\hline nRT & 3.06 & $1.49-6.26$ & 0.002 & 2.18 & $1.00-4.78$ & 0.05 \\
\hline $\begin{array}{l}\text { Tumor localization (cm } \\
\text { from anal verge) }\end{array}$ & & & 0.003 & & & 0.04 \\
\hline $6-10 \mathrm{~cm}$ vs $0-5 \mathrm{~cm}$ & 0.28 & $0.13-0.63$ & 0.002 & 0.36 & $0.15-0.82$ & 0.015 \\
\hline $11-15 \mathrm{~cm}$ vs $0-5 \mathrm{~cm}$ & 0.25 & $0.10-0.66$ & 0.005 & 0.36 & $0.13-0.99$ & 0.049 \\
\hline \multicolumn{7}{|c|}{ Outcome: overall LARS (minor + major) } \\
\hline
\end{tabular}

$O R$ ods ratio, $C I$ confidential interval, $n R T$ neoadjuvant radiotherapy

\section{Discussion}

Currently a multidisciplinary approach for the treatment of rectal cancer and the increase in "sphincter-saving" surgical techniques have significantly reduced the rate of definitive stoma, allowing the restoration of intestinal continuity in over $80 \%$ of patients after rectal resection. However, technical progress and improvement of oncological outcomes are associated with an important impact on patients' QoL defined as LARS and surgical approach plays a significant role. It has been widely discussed over the years that laparoscopic surgery represents a valid alternative to the open approach both for short-term outcomes (smaller incisions, better post-operative pain control, shorter hospital stay, longer rapid resumption of daily activities), and long-term oncological outcomes (comparable oncological radicality and rates of loco-regional recurrence). In particular, recognized advantages of a minimally invasive approach derive from the better vision and, as a consequence, preservation of anatomical structures such as nerve plexus and anal sphincter function, all contributing to a reduction of surgical trauma [24-29]. At our Center, the minimally invasive approach represents the standard of care for rectal cancer.

To the best of our knowledge our study is currently the only one in the literature that analyzes the association between LARS and exclusively laparoscopic TMEs and the aim of the study was to estimate the prevalence of LARS at our Center and to define LARS risk factors in patients undergoing laparoscopic surgery for rectal cancer.

LARS rates after rectal surgery are quite heterogeneous, influenced by different post-operative evaluation strategies, different surgical approaches (open surgery, laparoscopic, robotic) and different rates of risk factors (radiotherapy, obesity, tumor site, etc.). Croese et al. in 2018 published a meta-analysis, in which they analyzed 11 articles, reporting variable prevalence of LARS from 17 to $65.4 \%$ [21]. We report a $35.9 \%$ rate of both minor and major LARS in a consecutive series of 153 laparoscopic resections, including long course nRT $30.1 \%$ rate.
Neoadjuvant radiotherapy/chemo-radiotherapy are considered among the main risk factors of LARS. In the study conducted by Hughes, the risk of major LARS was 20 times higher in patients who had previously undergone nCRT $(p<0.001)$ [30]. Bondeven et al. demonstrated that nRT was an independent risk factor for major LARS (OR 3.5; 95\% CI 1.15-9.4) [13]. Peeters in 2005 demonstrated that neoadjuvant short-course radiotherapy followed by TME caused late side effects of intestinal dysfunction compared with surgery alone; equally in the Dutch Trial short-course nRT was a risk factor for major LARS (56\% nRT vs 36\% non-nRT; $p<0.01$ ) [16]. In 2019 Sun showed that patients undergoing long-course nRT had a more severe form of LARS and the QoL was worse [17]. None of the previous mentioned series includes only laparoscopic TMEs. In our laparoscopic series long course nRT was performed in 46 patients (30.1\%), more than half of whom (25 patients, 54.3\%) developed LARS $(p=0.003)$.

Furthermore, there is a general consensus on the distance from anal verge as risk factors of LARS. In Battersby's study, tumor localization within $6 \mathrm{~cm}$ of the anal margin was a high risk factor for severe LARS [12]. Bondeven, using post-operative Magnetic Resonance Imaging, evaluated what impact the height of the anastomosis had on post-operative bowel function: the risk of major LARS was $46 \%$ in patients with less than $4 \mathrm{~cm}$ of residual rectal stump compared to $10 \%$ in patients over $4 \mathrm{~cm}(p<0.0001)$ [13]. Similar results were obtained by Ekkarat in cases of lower anastomosis, less than $5 \mathrm{~cm}$ from the anal margin [15]. Similarly in our study $58.5 \%$ of patients affected by "low" rectal cancer developed LARS. Bregendahl analyzed a series of 938 patients who underwent rectal resection between 2001 and 2007 in Denmark, performing 555 TME (59\%): TME compared to PME (partial mesorectal excision) was significantly associated with the development of major LARS (OR 2.31; 95\% CI 1.69-3.16) [14]. In our study, a total of 116 TMEs (76.8\%) were performed. The association between TME and minor LARS $(p=0.408)$, major LARS $(p=0.347)$, overall LARS 
$(p=0.408)$ was not significant $(p=0.106)$. These data are probably due to the small size of the sample.

Also diverting stoma and delayed closure are associated with increased morbidity. Hughes in his 85 patients sample showed that stoma closure within 6 months was a protective factor for the development of LARS (OR $0.2 ; p<0.01$ ), while delayed closure increased the risk of developing LARS by 3.7 times [30]. In our series, a diverting stoma was performed in 73 patients $(47.7 \%)$, in 61 of these $(81.3 \%)$ it was closed after more than 3 months. The prevalence of overall LARS in patients with diverting stoma was $43.8 \%$ $(p=0.064)$, the prevalence of LARS in patients undergone delayed stoma closure (after 3 months) was $45.9 \%$ $(p=0.561)$ without statistical differences.

The type of colorectal anastomosis after resection also affects post-surgery morbidity, in particular intestinal function. According to the major randomized studies in the literature, the comparison between SCR (straight colo-rectal) anastomosis and J-pouch anastomosis shows that the creation of a new rectal reservoir reduces the frequency of defecation by $25-60 \%$ and varies the urgency from 0 to $100 \%$ [18]. In our study, the association between the type of anastomosis and the development of overall LARS was not significant $(p=0.409)$, since in almost all patients $(94.8 \%)$ a SCR anastomosis was performed and therefore the groups of patients with different types of anastomosis were not comparable.

Finally among anamnestic risk factors obesity seems to represent a predictor of LARS. In the ROLARR trial published by Bolton, Univariate Multivariate Logistic Regression Models for Each Predictor of Interest showed that a 10-unit increase in BMI was associated with an increase of 2.456 (95\% CI 0.942-6.348) in odds of major LARS [31]. In our series 11 patients had BMI $>30 \mathrm{~kg} / \mathrm{m}^{2}$. Seven patients (63.6\%) developed LARS, 3 of which reported the minor form and 4 the major form. BMI was not statistically associated with the development of overall LARS $(p=0.057)$, LARS minor $(p=0.177)$, LARS major $(p=0.263)$. The small size of the sample in our study may have affected the statistical significance of this data.

To date, several treatment options have been proposed for LARS, all mainly limited to symptom control. There is no well-defined standard protocol, but variable and patientbased. This includes antidiarrheal medications, anal plugs, biofeedback therapy, pelvic floor rehabilitation, colonic irrigation and nerve stimulation. Starting from the least invasive to the most invasive, these are used most frequently in combination, in order to obtain the best treatment for each patient. When all conservative treatments fail, a permanent stoma represents the ultimate option [23].

Main strengths of our work include sample homogeneity due to reduced patient recruitment time, low rate of missing data due to low patient loss rate at follow-up, and high response rate (almost all patients). Furthermore, to date, our study represents a novelty in the literature for its exclusively laparoscopic series. Patients were asked to answer the LARS Score questionnaire, referring to the first 12-18 months after surgery, in order to consider the typical time of LARS symptoms occurrence. We also performed a stratification of risk factors (anamnestic, pre-, intra- and post-operative), in order to evaluate the role of each on the prevalence of LARS. Finally, we included in the study patients who underwent surgery with only one type of surgical approach, to minimize the influence of the technique (open vs laparoscopic vs robotic) on the outcome. On the other hand, the retrospective analysis of a prospective database, the limited sample size and the inaccuracy of anastomotic height assessment represent the main limitations of our study.

Based on the aforementioned advantages of laparoscopy and on the etiology of the syndrome, it seems reasonable to expect a lower rate of LARS after laparoscopy compared with the open approach. However, the LARS rate in our series of laparoscopic resections remains high (35.9\%), consistent with the open TME literature. Ultimately, this raises the hypothesis that other risk factors such as nRT, tumor location and anastomotic distance are more influent than the surgical technique.

Considering the high morbidity of rectal surgery, we therefore believe that in all Colorectal Surgery Centers it is necessary to provide a perioperative work-up, including evaluation questionnaires (e.g. LARS Score, Wexner Score, etc.), functional tests (e.g. pre-operative ano-rectal manometry) and rehabilitation programs [e.g. biofeedback, pelvic floor muscle training (PFMT), rectal balloon training (RBT) and trans-anal irrigation (TAI)], in order to select the most suitable treatment for each patient, as already proposed by Martellucci with a treatment algorithm in a multimodal approach [32]. Further studies are needed to compare LARS rate when performing different types of surgical approaches (open vs minimally invasive) for rectal cancer.

In conclusion LARS is a complex, multifactorial syndrome with high prevalence after rectal surgery. In our laparoscopic series, LARS rate resulted consistent with the open TME literature. Neoadjuvant radiotherapy and tumor localization resulted independent risk factors for LARS. Tumor localization in the "middle" and "high" rectum resulted a protective factor compared to the localization in "low" rectum.

\section{Declarations}

Disclosures Drs. Antonella Nicotera, Ezio Falletto, Alberto Arezzo, Massimiliano Mistrangelo, Roberto Passera, Mario Morino have no conflicts of interest and did not receive any form of financial support of funding to complete this study. 
Open Access This article is licensed under a Creative Commons Attribution 4.0 International License, which permits use, sharing, adaptation, distribution and reproduction in any medium or format, as long as you give appropriate credit to the original author(s) and the source, provide a link to the Creative Commons licence, and indicate if changes were made. The images or other third party material in this article are included in the article's Creative Commons licence, unless indicated otherwise in a credit line to the material. If material is not included in the article's Creative Commons licence and your intended use is not permitted by statutory regulation or exceeds the permitted use, you will need to obtain permission directly from the copyright holder. To view a copy of this licence, visit http://creativecommons.org/licenses/by/4.0/.

\section{References}

1. Heald RJ (1988) The 'Holy Plane' of rectal surgery. J R Soc Med 81(9):503-508

2. MacFarlane JK, Ryall RD, Heald RJ (1993) Mesorectal excision for rectal cancer. Lancet 341:457-460

3. Cunningham D, Atkin W, Lenz HJ, Lynch HT, Minsky B, Nordlinger B, Starling N (2010) Colorectal cancer. Lancet 375:1030-1047

4. Van den Brink M, Stiggelbout AM, van den Hout WB, Kievit J, Klein Kranenbarg E, Marijnen CA, Nagtegaal ID, Rutten HJT, Wiggers T, Van de Velde CJH (2004) Clinical nature and prognosis of locally recurrent rectal cancer after total mesorectal excision with or without preoperative radiotherapy. J Clin Oncol 22(19):3958-3964

5. Detering R, Karthaus EG, Borstlap WAA, Marijnen CAM, Van de Velde CJH, Bemelman WA, Beets GL, Tanis PJ, Aalbers AGJ, Dutch Snapshot Research Group (2019) Treatment and survival of locally recurrent rectal cancer: a cross-sectional population study 15 years after the Dutch TME trial. Eur J Surg Oncol 45:2059-2069

6. Bryant CLC, Lunniss PJ, Knowles CH, Thaha MA, Chan CLH (2012) Anterior resection syndrome. Lancet Oncol 13:403-408

7. Williamson ME, Lewis WG, Finan PJ, Miller AS, Holdsworth PJ, Johnston D (1995) Recovery of physiologic and clinical function after low anterior resection of the rectum for carcinoma: myth or reality? Dis Colon Rectum 38:411-418

8. Pucciarelli S, Del Bianco P, Efficace F, Toppan P, Serpentini S, Friso ML, Lonardi S, De Salvo GL, Nitti D (2010) Health-related quality of life, faecal continence and bowel function in rectal cancer patients after chemoradiotherapy followed by radical surgery. Support Care Cancer 18(5):601-608

9. Horgan PG, O'Connell PR, Shinkwin CA, Kirwan WO (1989) Effect of anterior resection on anal sphincter function. Br J Surg 76:783-786

10. Farouk R, Duthie GS, Lee PW, Monson JR (1998) Endosonographic evidence of injury to the internal anal sphincter after low anterior resection: long-term follow-up. Dis Colon Rectum 41:888-891

11. Bretagnol F, Troubat H, Laurent C, Zerbib F, Saric J, Rullier E (2004) Long-term functional results after sphincter-saving resection for rectal cancer. Gastroenterol Clin Biol 28:155-159

12. Battersby NJ, Juul T, Christensen P, Janjua AZ, Branagan G, Emmertsen KJ, Norton C, Hughes R, Laurberg S, Moran BJ, United Kingdom Low Anterior Resection Syndrome Study Group (2016) Predicting the risk of bowel-related quality-of-life impairment after restorative resection for rectal cancer: a multicenter cross-sectional study. Dis Colon Rectum 59:270-280

13. Bondeven P, Emmertsen K, Laurberg S, Pedersen B (2015) Neoadjuvant therapy abolishes the functional benefits of a larger rectal remnant, as measured by magnetic resonance imaging after restorative rectal cancer surgery. Eur J Surg Oncol 41:1493-1499

14. Bregendahl S, Emmertsen KJ, Lous J, Laurberg S (2013) Bowel dysfunction after low anterior resection with and without neoadjuvant therapy for rectal cancer: a population-based crossectional study. Colorectal Dis 15:1130-1139

15. Ekkarat $\mathrm{P}$, Boonpipattanapong T, Tantiphlachiva K, Sangkhathat S (2016) Factors determining low anterior resection syndrome after rectal cancer resection: a study in Thai patients. Asian J Surg 39:225-231

16. Peeters KCMJ, van de Velde CJH, Leer JWH, Martijn H, Junggeburt JMC, Klein Kranenbarg E, Steup WH, Wiggers T, Rutten HJ, Marijnen CAM (2005) Late side effects of short-course preoperative radiotherapy combined with total mesorectal excision for rectal cancer: increased bowel dysfunction in irradiated patients-a Dutch Colorectal Cancer Group Study. J Clin Oncol 23:6199-6206

17. Sun W, Dou R, Chen J, Lai S, Zhang C, Ruan L, Kang L, Deng Y, Lan P, Wang L, Wang J (2019) Impact of long-course neoadjuvant radiation on postoperative low anterior resection syndrome and quality of life in rectal cancer: post hoc analysis of a randomized controlled trial. Ann Surg Oncol 26:746-755

18. Brown CJ, Fenech DS, McLeod RS (2008) Reconstructive techniques after rectal resection for rectal cancer. Cochrane Database Syst Rev 16(2):CD006040

19. Mochiki E, Nakabayashi T, Suzuki H, Haga N, Fujita K, Asao T, Kuwano H (2001) Barostat examination of proximal site of the anastomosis in patients with rectal cancer after low anterior resection. World J Surg 25:1377-1382

20. Iizuka I, Koda K, Seike K, Shimizu K, Takami Y, Fukuda H, Tsuchida D, Oda K, Takiguchi N, Miyazaki M (2004) Defecatory malfunction caused by motility disorder of the neorectum after anterior resection for rectal cancer. Am J Surg 188:176-180

21. Croese AD, Lonie JM, Trollope AF, Vangaveti VN, Ho Y (2018) A meta-analysis of the prevalence of low anterior resection syndrome and systematic review of risk factors. Int J Surg $56: 234-241$

22. Emmertsen KJ, Laurberg S (2012) Low anterior resection syndrome score: development and validation of a symptom-based scoring system for bowel dysfunction after low anterior resection for rectal cancer. Ann Surg 255:922-928

23. Dulskas A, Smolskas E, Kildusiene I, Samalavicius NE (2018) Treatment possibilities for low anterior resection syndrome: a review of the literature. Int J Colorectal Dis 33:251-260

24. Guillou PJ, Quirke P, Thorpe H, Walker J, Jayne DG, Smith AM, Heath RM, Brown JM, MRC CLASICC trial group (2005) Shortterm endpoints of conventional versus laparoscopic-assisted surgery in patients with colorectal cancer (MRC CLASICC trial): multicentre, randomised controlled trial. Lancet 365:1718-1726

25. van der Pas MH, Haglind E, Cuesta MA, Fürst A, Lacy AM, Hop WC, Bonjer HJ, COlorectal cancer Laparoscopic or Open Resection II (COLOR II) Study Group (2013) Laparoscopic versus open surgery for rectal cancer (COLOR II): short-term outcomes of a randomised, phase 3 trial. Lancet Oncol 14:210-218

26. Kang SB, Park JW, Jeong SY, Nam BH, Choi HS, Kim DW, Lim SB, Lee TG, Kim DY, Kim JS, Chang HJ, Lee HS, Kim SY, Jung KH, Hong YS, Kim JH, Sohn DK, Kim DH, Oh JH (2010) Open versus laparoscopic surgery for mid or low rectal cancer after neoadjuvant chemoradiotherapy (COREAN trial): short-term outcomes of an open-label randomised controlled trial. Lancet Oncol 11:637-645

27. Jayne DG, Thorpe HC, Copeland J, Quirke P, Brown JM, Guillou PJ (2010) Five-year follow-up of the Medical Research Council CLASICC trial of laparoscopically assisted versus open surgery for colorectal cancer. Br J Surg 97:1638-1645 
28. Green BL, Marshall HC, Collinson F, Quirke P, Guillou P, Jayne DG, Brown JM (2013) Long-term follow-up of the Medical Research Council CLASICC trial of conventional versus laparoscopically assisted resection in colorectal cancer. Br J Surg 100:75-82

29. Bonjer HJ, Deijen CL, Abis GA, Cuesta MA, van der Pas MH, de Lange-de Klerk ESM, Lacy AM, Bemelman WA, Andersson J, Angenete E, Rosenberg J, Fuerst A, Haglind E, COLOR II Study Group (2015) A randomized trial of laparoscopic versus open surgery for rectal cancer. N Engl J Med 372:1324-1332

30. Hughes D, Cornish J, Morris C (2017) Functional outcome following rectal surgery-predisposing factors for low anterior resection syndrome. Int J Colorectal Dis 32:691-697
31. Bolton WS, Chapman SJ, Corrigan N, Croft J, Collinson F, Brown JM, Jayne DG (2020) The Incidence of Low Anterior Resection Syndrome as Assessed in an International Randomized Controlled Trial (MRC/NIHR ROLARR). Ann Surg 274:e1223-e1229

32. Martellucci J (2016) Low anterior resection syndrome: a treatment algorithm. Dis Colon Rectum 59:79-82

Publisher's Note Springer Nature remains neutral with regard to jurisdictional claims in published maps and institutional affiliations. 